\title{
Feasibility Study of Partial Discharge Detection of Electrical Assets Based on Electromagnetic Field Emissions
}

\author{
Nayli Adriana Azhar', Norazizah Mohd Aripin² \\ ${ }^{1}$ College of Engineering, Universiti Tenaga Nasional, Putrajaya Campus, Kajang-43000, Malaysia Malaysia, \\ nayli.adriana@uniten.edu.my \\ ${ }^{2}$ College of Engineering, Universiti Tenaga Nasional, Putrajaya Campus, Kajang-43000, Malaysia, \\ norazizahm@uniten.edu.my
}

\begin{abstract}
Early detection of partial discharge (PD) in high voltage equipment allows for the necessary interventions to be taken and is essential in preventing catastrophic breakdown due to faults. PD detection may be achieved by usage of various PD detectors such as acoustic, electrical, optical, ultrasonic and UHF detection methods. This paper focuses on UHF detection method, in which the UHF antenna can be regarded as sensor to obtain the induced electromagnetic waves from the PD source. This technique uses a microstrip patch antenna to detect the PD signal within the UHF range. The microstrip patch antenna for PD detection is cost-effective, lightweight, easy to design and fabricate. A T-shaped microstrip patch antenna at the ground plane is anticipated to improve the antenna performances. The anticipated T-shaped partial ground microstrip patch antenna utilises FR4 substrate with substrate thickness, $\mathrm{Hs}=1.6$ mmand dielectric constant, $\varepsilon r=4.3$. The proposed antenna is simulated using CST Microwave Studio, fabricated on FR4 and validated using a vector network analyzer, to attain the desired performance. The simulation results demonstrated the following performances; $-48 \mathrm{~dB}$ for return loss, 1.008 for voltage standing wave ratio (VSWR) and $1.951 \mathrm{~dB}$ gain at $500 \mathrm{MHz}$. The results from fabricated antenna showed that the proposed antenna achieved return loss of $-28.83 \mathrm{~dB}$ with VSWR of 1.26. Results from both simulation design and fabricated antenna confirmed that the anticipated T-shaped microstrip patch antenna is suitable for PD detection at UHF range.
\end{abstract}

Key words: VSWR; Return Loss; Microstrip Patch Antenna; UHF; Partial Discharge

\section{INTRODUCTION}

Partial discharge (PD) is often defined as an electric discharge which bridges the insulation between conductors only partially. PD may or may not occur near a conductor and may even occur inside a medium or high voltage discharge in a high voltage equipment and power system are high concentration and high intensity of electric field. Another possible cause of PD is the presence of impurities in the insulating oil. An electric field may be generated at the interface with a severe distortion due to the different medium combination. Partial discharge may lead to small spots of burn marks developing at the solid insulation [2]. This discharge will effect in gradual insulation deterioration and consequently, could result in total equipment failure. Therefore, early PD detection is crucial in eliminating high voltage equipment breakdown and to maintain the reliability of a high voltage power system's operation. Partial discharge can be detected and measured by using several methods, such as acoustic detection, electrical detection, optical detection and UHF detection methods [3].

Electrical method has been used for decades to measure short circuit current flow in insulation. The electrical method has some limitations and is less accurate since it requires an onsite testing [4]. The acoustic method is mainly based on capturing pressure waves from vaporisation that occurs in materials [5]. In optical detection, light emissions are used to monitor the partial discharges [6].

The UHF detection method is advantageous owing to the fact that partial discharge frequencies lies within the UHF range. PD signal frequency ranges from $300 \mathrm{MHz}$ to $1.5 \mathrm{GHz}$, while the UHF ranges from $300 \mathrm{MHz}$ to $3 \mathrm{GHz}$ and explains why the UHF detection method is widely used. UHF detection method is also preferable due to its immunity to electromagnetic interference [7]. Therefore, in comparison to the other detection methods, it can be deployed for on-site testing. In [17], it is reported that microstrip patch antenna able to detect a partial discharge signal as low as $19 \mathrm{pC}$, which is equivalent to $100 \mathrm{mV}$ [17]. This allows the detection of severity of a defect in any high voltage equipment. The UHF sensor can be classified into internal or external couplers, which can either be mounted inside or outside any high voltage equipment, making the UHF sensor convenient. Other advantages of using UHF sensors are that they are highly sensitive and are able to reduce disturbance for more accurate readings on the partial discharge emissions. 
To design a UHF antenna specifically for PD, the following design necessities should be considered:

a) The frequency band of the UHF antenna, ranging from $300 \mathrm{MHz}$ to $1500 \mathrm{MHz}$, should be within the PD signal. The $\mathrm{UHF}$ antenna is considered to be resonant at $500 \mathrm{MHz}$ for this mission. The resonant frequency of $500 \mathrm{MHz}$ is chosen based on the imitation and experiment conducted on high voltage switchgear [8] and high voltage apparatus [9]. In [9], it is reported that the UHF PD sensor is able to detect PD signal over a $6 \mathrm{~m}$ distance.

b) The UHF antenna should be designed to include an omnidirectional radiation pattern which can receive signals from all directions. This criterion is important since the position of the source of PD is usually unknown. The omnidirectional antenna will then have better efficiency in the identification of the PD signal.

c) The UHF antenna also requires a higher gain so that it can radiate well.

PD detection in high voltage equipment mainly depends on the UHF sensor performances. The UHF method has been proven to be efficient, especially in power transformers in terms of partial discharges localisation [10] and its' immunity against external electromagnetic interference and signal-to-noise ratio [11]. This helps to eliminate noise within a substation, especially in the lower frequency range (less than $200 \mathrm{MHz}$ ). Good sensitivity and ability to detect partial discharges require a good UHF sensor [12]. A common UHF sensor design process includes a software simulation, such as CST Microwave Studio and a prototype fabrication by using a printed circuit board (PCB).

There are various UHF sensors that can be used for PD detection, such as monopole antenna, fractal antenna, Vivaldi antenna and microstrip patch antenna. Monopole antenna is where different types and lengths of the monopole antenna are tested to detect the PD signals emitted from $1300 \mathrm{MHz}$ to $1900 \mathrm{MHz}$ range [13]. In [14], fractal antenna is designed to operate on various impedance bandwidth (narrowband, wideband, or multiband) by adjusting the antenna dimensions. In [15], the Vivaldi antenna is designed to operate from $510 \mathrm{MHz}$ to $825 \mathrm{MHz}$ and $950 \mathrm{MHz}$ to $2 \mathrm{GHz}$. The fractal antenna is also designed to notch the interference of GSM band from $890 \mathrm{MHz}$ to $960 \mathrm{MHz}$. In [10], microstrip patch antenna with frequency that varies from 340 $\mathrm{MHz}$ to $1490 \mathrm{MHz}$, which lies in the PD frequency spectrum of $300 \mathrm{MHz}$ to $1500 \mathrm{MHz}$ was proposed. Each of the UHF sensors has its own advantages, constraints, design, and operating characteristic such as the ability to detect and the distance from the partial discharge signal.

In designing a UHF sensor, especially the microstrip patch antenna, some criteria are crucial in determining its functionality to detect the partial discharge signal in HV equipment. The microstrip patch antenna is chosen mainly due to its favourable characteristics - lightweight, low fabrication cost and ease of installation. However, its' main constraint are narrow bandwidth and low gain. Serious efforts started among researchers and scientists to overcome these limitations. One of the techniques to improve the bandwidth is by optimizing the antenna's geometrical shape. In [9], B. Sarkar et.al proposed a standard microstrip patch antenna structure with a frequency of $500 \mathrm{MHz}$ using PVC as the substrate material. The paper proposed a narrow bandwidth of $30 \mathrm{MHz}$ and the experimental setup proved that the patch antenna is able detect the PD signal in high voltage equipment.

In [8], F. Yang et.al proposed a UWB microstrip patch antenna that covers the most part of the PD frequency range, from $500 \mathrm{MHz}$ to $1500 \mathrm{MHz}$. UWB antenna is mainly used in power transformers and Gas-Insulated Switchgears (GIS). However, the UWB antenna is usually large in size and inconvenient for the system to install or to move [16]. It also can cause high external noise and may lead to some remarkable distortion as mentioned in [11].For this project, a narrow bandwidth microstrip patch antenna is proposed, with resonant frequency of $500 \mathrm{MHz}$, while at the same time covering the PD signal frequency ranging from $300 \mathrm{MHz}$ to $700 \mathrm{MHz}$.

\section{MATERIAL AND METHOD}

When constructing a microstrip patch antenna, there are many factors that need to be carefully considered, such as the substrate content, the patch's physical properties, and the feeding method. Geometrical shapes of the antenna also playsan important part in the antenna design that affects the overall antenna performances [19].

FR4, RT Duroid, PVC, and Roger 4350 are among commonly used substrate in a microstrip patch antenna. The substrate is typically withstandard dielectric constant, ranges at $2.2<<\varepsilon r<<12$ [18]. Generally, lower dielectric constant is preferable as it would provide higher efficiency, larger bandwidth and better radiation power. However, this may lead to larger antenna dimension. In contrast, higher dielectric constraint provides smaller antenna dimension with less efficiency and narrow bandwidth. Therefore, an optimal design should balance the trade-off between antenna dimension and antenna performance. The geometrical shapes can be either rectangular, square, circle or any complex design depending on the antenna parameters and design requirements. Choosing an optimal geometrical shape will determine the resonant frequency, bandwidth, polarization and radiation characteristics.

There are basically four feeding methods for microstrip antenna, namely; inset feeding, aperture coupling, proximity coupling and coaxial feeding. A conducting strip is attached directly to the edge using inset feeding, on the same substratum of the microstrip patch antenna. This helps the antenna to have a planar configuration and hence has improved impedance balancing compared to other feeding strategies. [20].Thus, the inset feeding technique is used in this work. 
Antenna performances are commonly evaluated in terms of the resonant frequency, bandwidth, return loss (S11), voltage standing wave ratio (VSWR), directivity and gain. In this work, the microstrip patch antenna is considered to operate between $300 \mathrm{MHz}$ to $700 \mathrm{MHz}$, with target resonant frequency of $500 \mathrm{MHz}$. This isin compliance with the PD signal frequency band. A good antenna design should achieve the return loss, S11 of less than $-10 \mathrm{~dB}$. It resources that only $10 \%$ of the power signal is reflected back and the remaining $90 \%$ of power shall be absorbed by the antenna[21]. Return loss value is often related to VSWR, whereby the lower the return loss value, the lower the VSWR (approaches to 1 (unity)). The standard VSWR requirement for antenna is less than 2 . Directivity evaluates the concentration of antenna radiation pattern in a given direction. Directivity is often expressed in $\mathrm{dBi}$. An omnidirectional antenna able to radiates and receives signals in all directions. PD locations are typically unknown, hence omnidirectional antenna is preferable than the directional antenna. Antenna gain is characterised as radiation efficiency times the directivity of the antenna. Mathematically, the gain can be expressed as:

$$
\mathrm{G}=\eta \mathrm{D}
$$

$$
\text { Where } \eta=\text { efficiency, } \mathrm{D}=\text { directivity }
$$

Negative gain in $\mathrm{dBi}$ means that the antenna is not efficient and not radiating well in all direction.

The basic structure of microstrip patch antenna is shown in Fig. 1. The field view of the FR4 substrate antenna design with double copper cladding for the ground plane and the feedline is shown in Fig. 2. Dielectric constant, $\varepsilon r$ of 4.3 and substrate thickness, Hs of $1.6 \mathrm{~mm}$, are found in the FR4 substrate. The FR4 is chosen due to the availability, cost, easy to fabricate and it is suitable for operating frequency less than $1 \mathrm{GHz}$.

Researchers have proposed various techniques to improve the return loss, frequency bandwidth and antenna gain. Among other techniques include parasitic elements, defect ground, feeding technique and partial ground. In this work, the microstrip patch antenna with a T-shaped partial ground plane is proposed. Fig. 3 illustrates the proposed T-shape structure.

To build and evaluate the performance of the antenna, CST Microwave Studio software is used. Table I tabulates the optimised parameters for the microstrip patch antenna with a $\mathrm{T}$-shaped partial ground technique.

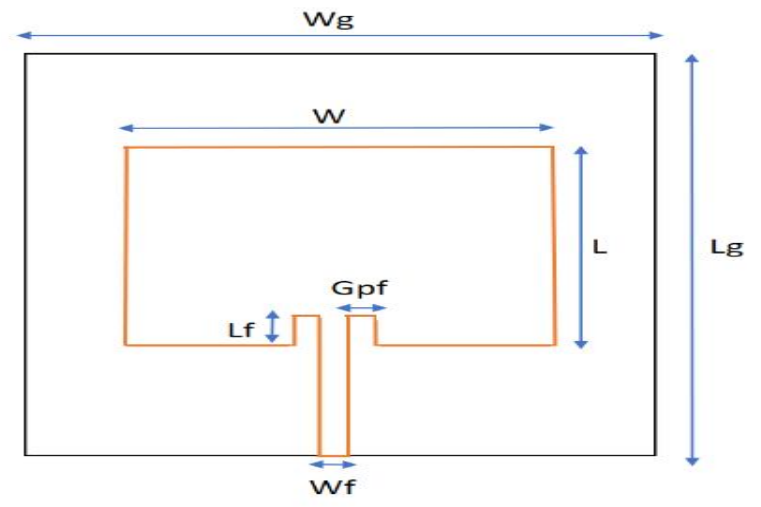

Figure 1: The basic structure of microstrip patch antenna

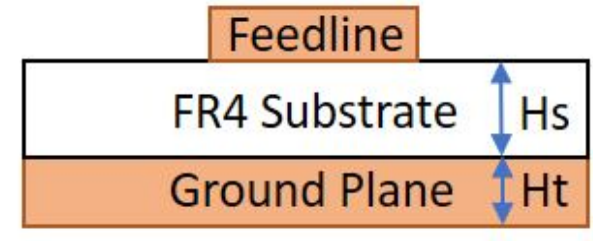

Figure 2: The ground view of the antenna

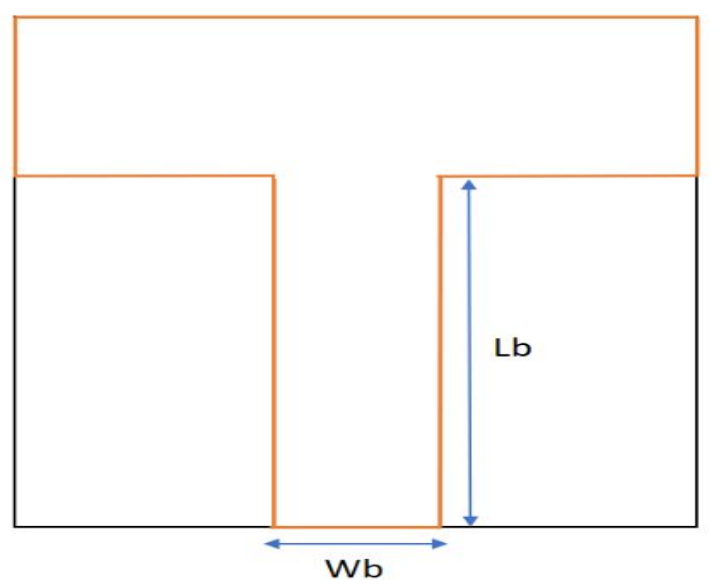

Figure 3: The T-shaped structure at the ground plane of the designed microstrip patch antenna

Table I: The Optimised Parameters Of The Proposed Microstrip Patch Antenna

\begin{tabular}{|l|l|}
\hline Parameters & Dimensions (mm) \\
\hline Antenna Length,L & 140 \\
\hline Antenna Width,W & 76 \\
\hline Substrate Length, Lg & 226 \\
\hline Substrate Width, Wg & 84 \\
\hline Feedline Width, Wf & 3 \\
\hline Feedline Length, Lf & 15 \\
\hline Partial Ground Length, Lb & 192 \\
\hline Feedline Gap, Gpf & 1 \\
\hline Substrate Height, Hs & 1.6 \\
\hline Partial Ground Width, Wb & 20 \\
\hline Copper Height, Ht & 0.035 \\
\hline
\end{tabular}




\section{RESULTS AND DISCUSSION}

Fig. 4 shows the antenna structure of the proposed microstrip patch. The optimized T-shaped ground plane is shown in Fig. 5. While Fig. 6 illustrates the microstrip patch antenna with a full ground plane. In terms of return loss, gain, bandwidth, VSWR, and directivity, the performance of the T-shaped ground plane microstrip patch antenna is comparable to the full ground plane microstrip patch antenna.

Fig. 7 depicts the return loss of the full ground plane (represented by dotted line) and the proposed T-shaped partial ground (represented by solid line).At resonant frequency of $500 \mathrm{MHz}$, the T-shaped partial ground microstrip patch antenna obtained return loss (S11) value of $48 \mathrm{~dB}$. Whereas the full ground microstrip patch antenna achieved S11 value of $-16.25 \mathrm{~dB}$. Therefore, both antennas fulfilled the standard requirement of S11 that should be below $-10 \mathrm{~dB}$. The $\mathrm{S} 11$ parameter is also used as reference to determine the antenna bandwidth. At two intersections with a return loss of $-10 \mathrm{~dB}$, Fig. 7 shows that $68 \mathrm{MHz}$ ( $474 \mathrm{MHz}$ to $542 \mathrm{MHz}$ ) of bandwidth was reached by the planned Tshaped partial ground microstrip patch antenna. On the other hand, the full ground microstrip patch antenna achieved narrower bandwidth of $11 \mathrm{MHz}$ (from $495 \mathrm{MHz}$ to 506 $\mathrm{MHz}$ ). This shows explicitly that the anticipated T-shaped partial ground microstrip patch antenna, as well as the bandwidth, has greatly increased the return loss.

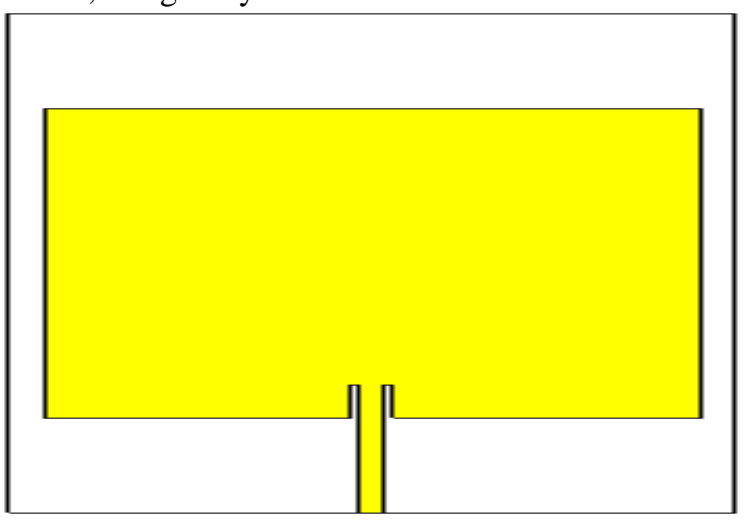

Figure 4: The front view of the microstrip patch antenna

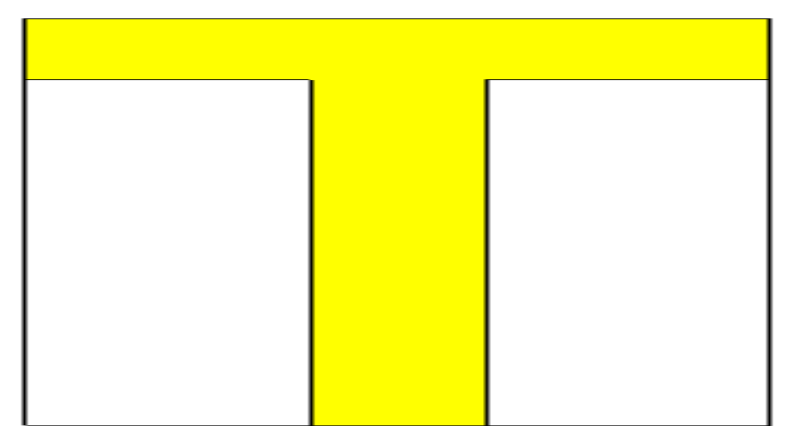

Figure 5: The T-shaped at the ground plane of the microstrip patch antenna

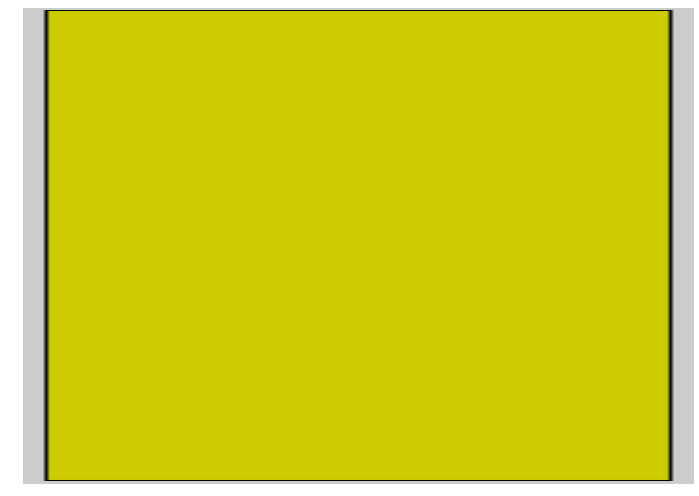

Figure 6: The full ground plane of the microstrip patch antenna

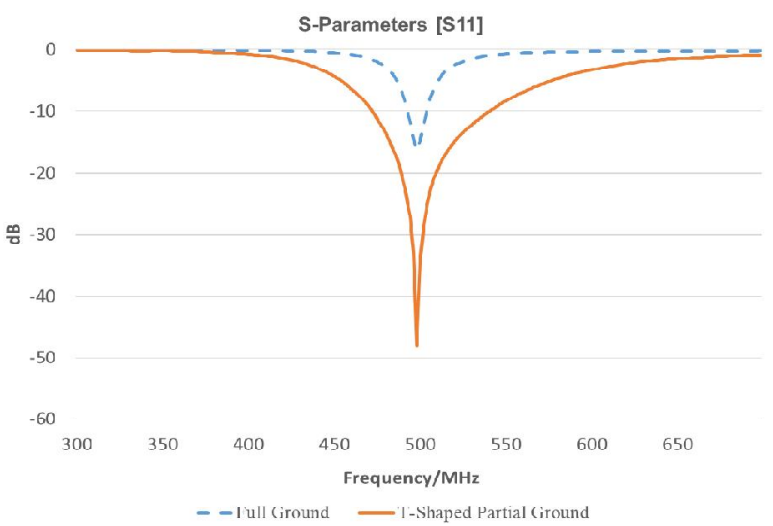

Figure 7: Return loss (S11) value of the proposed T-shaped partial ground antenna and the full ground antenna

The overall VSWR values for frequency range of $300 \mathrm{MHz}$ to $700 \mathrm{MHz}$ is shown in Fig. 8. Fig. 9 depicts that at 500 $\mathrm{MHz}$ resonant frequency, the proposed $\mathrm{T}$-shaped partial ground microstrip patch antenna obtained VSWR of 1.008, while the full ground microstrip patch antenna attained VSWR of 1.365 . As mentioned earlier, the return loss and VSWR are related to one another. Smaller VSWR is considered good and would means that the antenna is matched to the transmission line and more power is potentially be radiated.

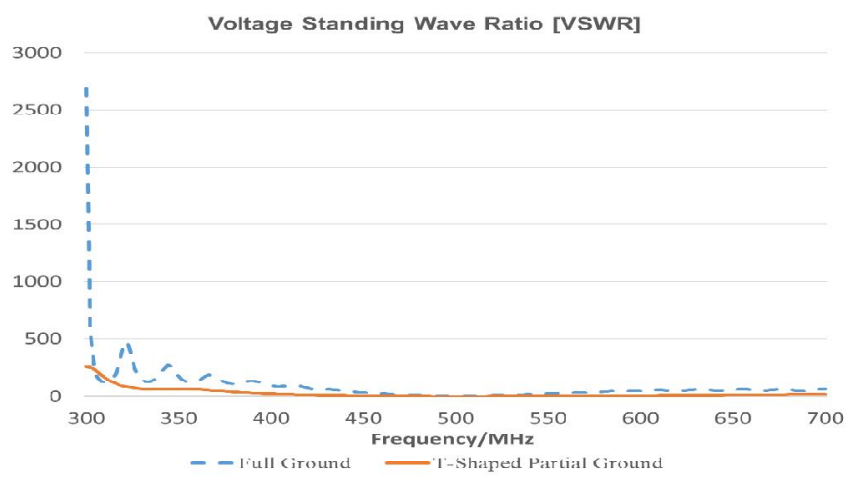

Figure 8: The VSWR value of the proposed T-shaped partial ground antenna and the full ground antenna 


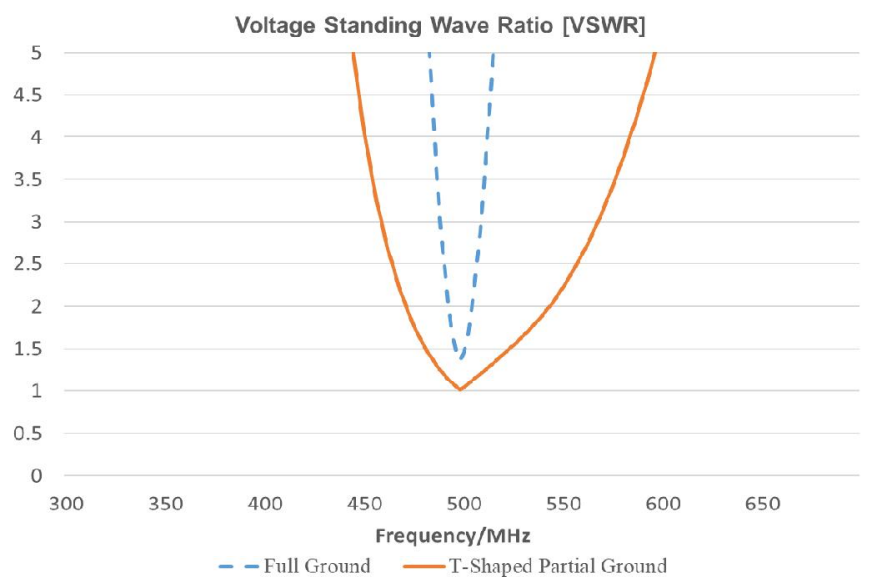

Figure 9: The closure view of VSWR value for both T-shaped partial ground antenna and full ground antenna

Fig. 10 illustrates the antenna gain for frequencyfrom 300 $\mathrm{MHz}$ to $700 \mathrm{MHz}$. It is observed that the full ground microstrip patch antenna obtained negative gain, which indicates that the antenna does not radiates efficiently.It may be caused by its' geometrical shape, poor impedance matching and also internal losses. In contrast, the proposed T-shaped partial ground microstrip patch antenna realized better gain, with maximum antenna gain of $1.358 \mathrm{~dB}$. Although the gain is not substantially high, it is sufficient to detect PD signal. Typically, higher antenna gain is desirable at the transmitting antenna. In this work, the proposed antenna will act as the receiving antenna, to detect the emitted PD signal.

Fig. 11 depicts that the full ground antenna recorded directivity of $4.033 \mathrm{dBi}$. Conversely, Fig. 12 shows that the proposed $\mathrm{T}$-shaped partial ground antenna obtained lower directivity of $2.538 \mathrm{dBi}$. Both antennae demonstrate omnidirectional, which indicates that it could radiate and receives energy equally well in all directions instead of being directional. With unknown location of PD source, omnidirectional antenna would allow more reliable detection.

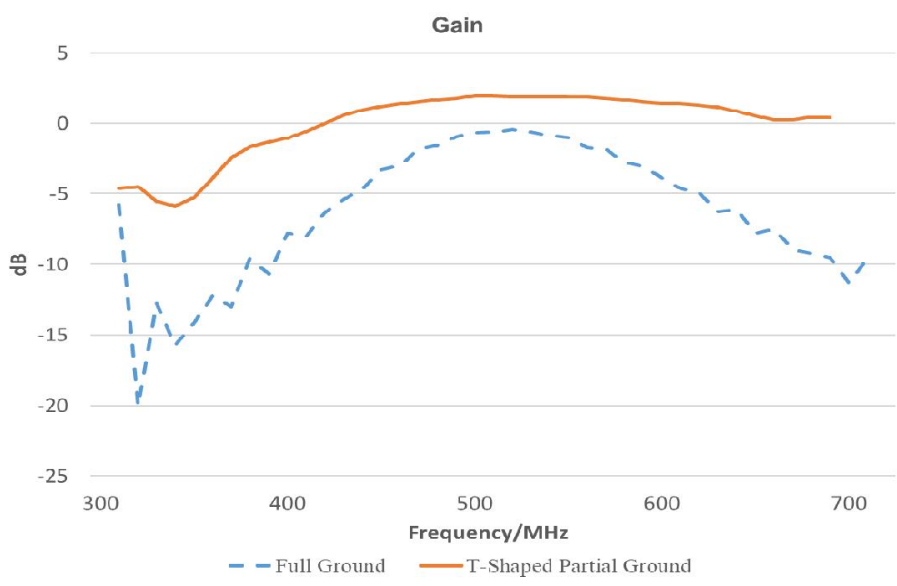

Figure 10: Gain of the proposed T-shaped partial ground antenna and the full ground antenna

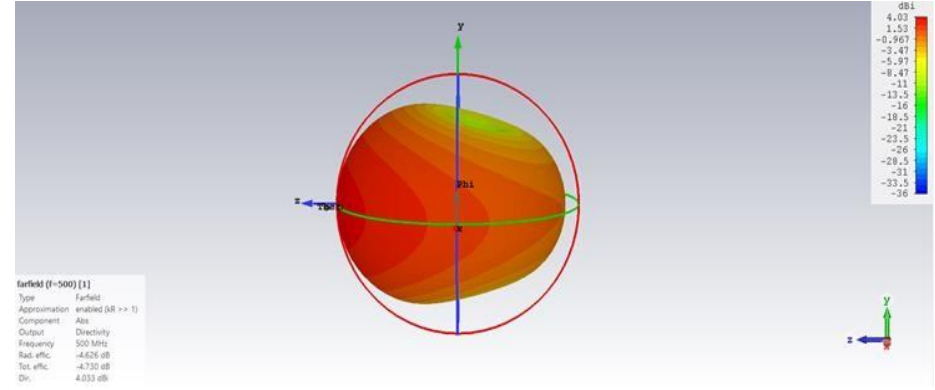

Figure 11: The directivity of full ground technique

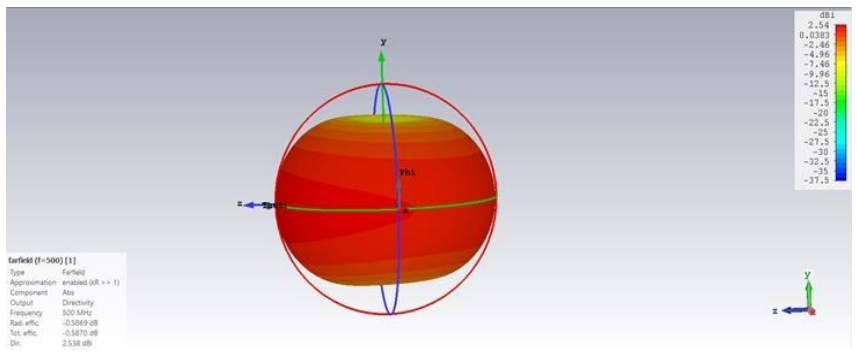

Figure 12: The directivity of T-shaped partial ground technique

The simulation results are then compared with the fabricated antenna, tested using vector network analyzer.The fabricated $\mathrm{T}$-shaped partial ground microstrip patch antenna is shown in Fig. 13. While Fig. 14 shows the T-shaped back view at the ground plane.

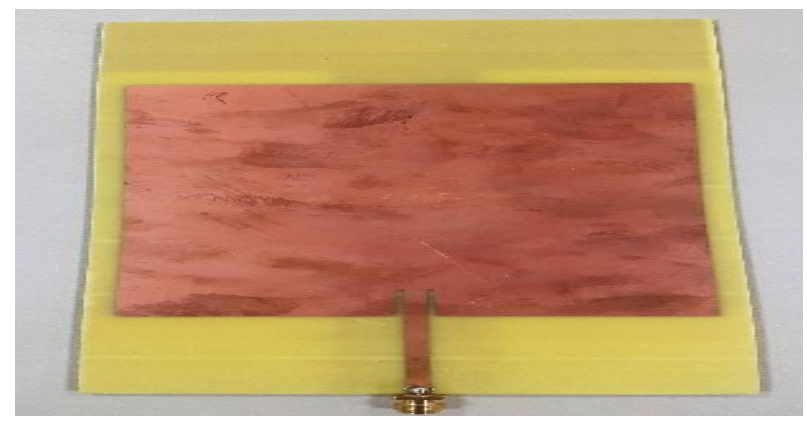

Figure 13: Photograph of the fabricated microstrip patch antenna

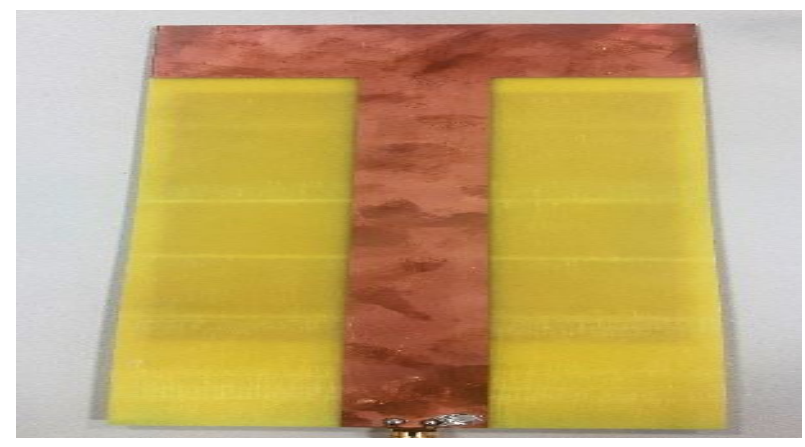

Figure 14: Photograph of the T-shaped partial ground of fabricated microstrip patch antenna 
As shown in Fig.15, the fabricated antenna attained resonant frequency of $504 \mathrm{MHz}$, return loss (S11) of -28.83 dBand bandwidth of $58 \mathrm{MHz}$ (frequency ranging from $468 \mathrm{MHz}$ to $526 \mathrm{MHz}$ ). The VSWR performance is also compared and the findingis illustrated in Fig. 16. As depicted in Fig. 17, the VSWR of the fabricated T-shaped partial ground microstrip patch antenna at $504 \mathrm{MHz}$ is 1.26 . Although the VSWR is slightly higher than the simulation, it still fulfils the VSWR requirement of less than 2 . Table II tabulates the simulation results of full ground and T-shaped partial ground microstrip patch antenna. While Table III summarizes the results of simulated and fabricated T- shaped partial groundmicrostrip patch antenna.

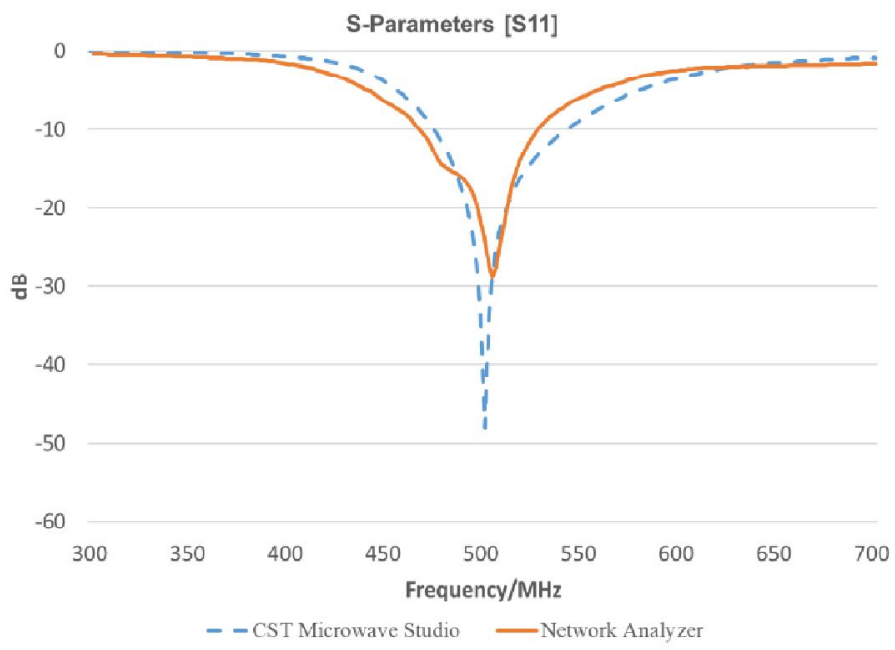

Figure 15: Return loss comparison of CST Microwave Studio software and Network Analyser

Voltage Standing Wave Ratio [VSWR]

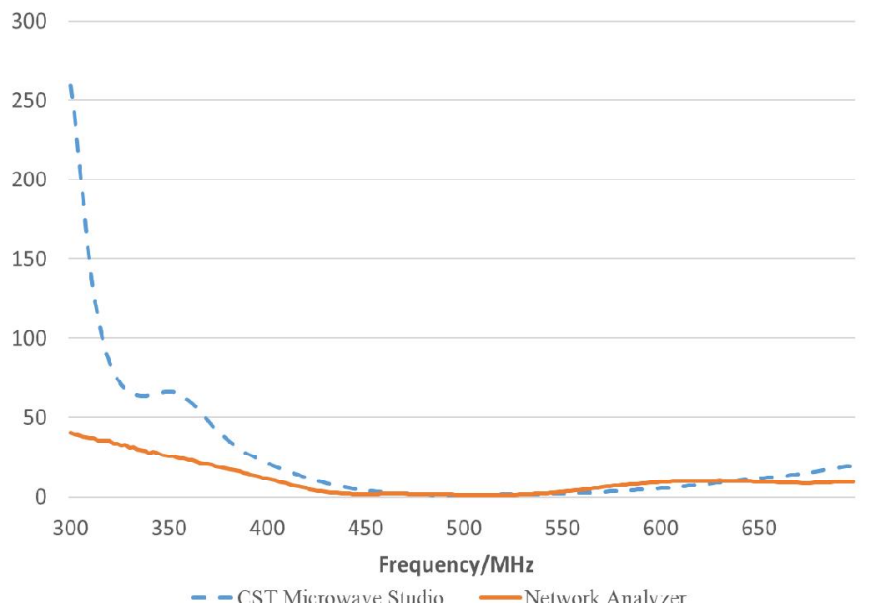

Figure 16: Comparison of VSWR for CST Microwave Studio software and Network Analyser.

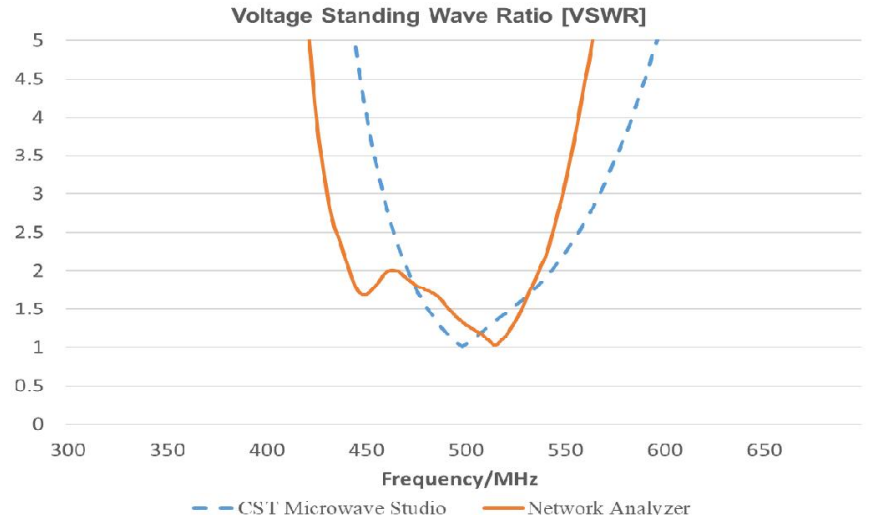

Figure 17: Closure comparison of VSWR for CST Microwave Studio software and Network Analyser

The complete performance of the fabricated T-shaped partial field microstrip patch antenna is very significantly different relative to the virtual antenna. It may be attributed to many variables, such as long-term exposure content oxidation, FR4 layer efficiency and manufacturing losses. Whereas the effects simulated are from optimal settings. It can however be inferred that, with acceptable consensus, the simulated outcome is very similar to the experimental outcome.

Table 2: Performance of full ground vs. T-shaped partial ground microstrip patch antenna

\begin{tabular}{|l|l|l|}
\hline & \multicolumn{2}{|l|}{ CST Microwave Studio Software } \\
\hline & Full Ground & $\begin{array}{l}\text { T-Shaped Partial } \\
\text { Ground }\end{array}$ \\
\hline Frequency & $500 \mathrm{MHz}$ & $500 \mathrm{MHz}$ \\
\hline Bandwidth & $495 \mathrm{MHz}-506 \mathrm{MHz}$ & $\begin{array}{l}474 \mathrm{MHz}-542 \\
\mathrm{MHz}\end{array}$ \\
\hline $\begin{array}{l}\text { Return } \\
\text { Loss }\end{array}$ & $-16.25 \mathrm{~dB}$ & $-48 \mathrm{~dB}$ \\
\hline VSWR & 1.365 & 1.008 \\
\hline Gain & $-0.5931 \mathrm{~dB}$ & $1.951 \mathrm{~dB}$ \\
\hline
\end{tabular}

Table 3: Performance Comparison Of Simulated Vs Fabricated TShaped Partial Ground Microstrip Patch Antenna

\begin{tabular}{|l|l|l|}
\hline & $\begin{array}{l}\text { CST Microwave } \\
\text { Studio Software }\end{array}$ & $\begin{array}{l}\text { Vector Network } \\
\text { Analyser }\end{array}$ \\
\hline Frequency & $500 \mathrm{MHz}$ & $504 \mathrm{MHz}$ \\
\hline Bandwidth & $474 \mathrm{MHz}-542 \mathrm{MHz}$ & $\begin{array}{l}468 \mathrm{MHz}-526 \\
\mathrm{MHz}\end{array}$ \\
\hline $\begin{array}{l}\text { Return } \\
\text { Loss }\end{array}$ & $-48 \mathrm{Db}$ & $-28.83 \mathrm{~dB}$ \\
\hline VSWR & 1.008 & 1.26 \\
\hline
\end{tabular}

\section{CONCLUSIONS}

This paper introduces the suggested T-shaped partial ground microstrip patch antenna that can be utilized in high voltage equipment for partial discharge detection. The proposed antenna is intended for the identification of PD signals emitted within the UHF range, precisely between $300 \mathrm{MHz}$ 
and $700 \mathrm{MHz}$ with a $500 \mathrm{MHz}$ resonant frequency. The proposed antenna is considered and replicated using the programme CST Microwave Studio, produced on a 4.3 dielectric constant FR4 substrate. The findings of the simulation have shown that the proposed T-shaped partial ground microstrip antenna satisfies the UHF antenna configuration criteria for PD detection. In terms of bandwidth, VSWR, return loss and gain, the suggested antenna even outperformed the full ground microstrip patch antenna. The constructed antenna is validated using an analyzer for the vector network. Although the general performance of the fabricated antenna is slightly inferior to the simulated design, it is still within good agreement. In future, reception test of the proposed antenna shall be carried out to further validate its accuracy and reliability in detecting the PD signal emitted by high voltage equipment.

\section{ACKNOWLEDGEMENT}

A special thank you for research grants under the Uniten Internal Grant 2018 (UNIIG 2018) to the Innovation \& Research Management Center (iRMC), Universiti Tenaga Nasional.

\section{REFERENCES}

[1] IEEE, The Authoritative Dictionary of IEEE Standards Terms Seventh Edition. 2000.

[2] Q. Wu, G. Liu, Z. Xia, and L. Lu, "The study of Archimedean spiral antenna for partial discharge measurement," Proc. 2013 Int. Conf. Intell. Control Inf. Process. ICICIP 2013, pp. 694-698, 2013.

[3] I.A. Soomro and N. Ramdon, "Study on different techniques of partial discharge (PD ) detection in power transformers winding: Simulation between paper and EPOXY resin using UHF method," Int. J. Conceptions Electr. Electron. Eng., vol. 2, no. April, pp. 57-61, 2014.

[4] A.Mukhtaruddin, M. Isa, M. R. Adzman, S. I. S. Hasan, M. N. K. H. Rohani, and C. C. Yii, "Techniques on partial discharge detection and location determination in power transformer," 2016 3rd Int. Conf. Electron. Des. ICED 2016, pp. 537-542, 2017.

[5] M. Mondal and G. B. Kumbhar, "Detection, Measurement, and Classification of Partial Discharge in a Power Transformer: Methods, Trends, and Future Research," IETE Tech. Rev. (Institution Electron. Telecommun. Eng. India), vol. 35, no. 5, pp. 483-493, 2018.

[6] W. E. P. S. Ediriweera, K. S. Priyanayana, R. M. A. P. Rajakaruna, R. A. K. G. Ranasinghe, J. R. Lucas, and R. Samarasinghe, "Microstrip Patch Antenna for Partial Discharge detection as a condition monitoring tool of power system assets," 3rd Int. Moratuwa Eng. Res. Conf. MERCon 2017, pp. 368-372, 2017.

[7] N. De Kock, B. Coric, and R. Pietsch, "UHF PD detection in gas-insulated switchgear - Suitability and sensitivity of the UHF method in comparison with the IEC 270 method," IEEE Electr. Insul. Mag., vol. 12, no. 6, pp. 20-26, 1996.
[8] F. Yang, C. Peng, Q. Yang, H. Luo, I. Ullah, and Y. Yang, "an Uwb Printed Antenna for Partial Discharge Uhf Detection in High Voltage Switchgears," Prog. Electromagn. Res. C, vol. 69, no. May, pp. 105-114, 2016.

[9] B. Sarkar, C. Koley, N. K. Roy, and P. Kumbhakar, "Low cost RF sensor for partial discharge detection of high voltage apparatus," 2013 IEEE 1st Int. Conf. Cond. Assess. Tech. Electr. Syst. IEEE CATCON 2013 - Proc., pp. 259-264, 2013.

[10] G. V. R. Xavier, E. G. Da Costa, A. J. R. Serres, H. F. S. Sousa, A. C. De Oliveira, and L. A. M. M. Nobrega, "Design and Application of an UHF Microstrip Circular Antenna for Partial Discharges Detection in Power Transformers," ICHVE 2018 - 2018 IEEE Int. Conf. High Volt. Eng. Appl., pp. 2-5, 2019.

[11] H. Chai, B. T. Phung, and S. Mitchell, "Application of UHF sensors in power system equipment for partial discharge detection: A review," Sensors (Switzerland), vol. 19, no. 5, 2019.

[12] Guoli Wang, YanpengHao, and Yanming Li, "Study on the ultra-high-frequency sensors for PD detection in power transformer," no. 1, pp. 793-796, 2002.

[13] G. Robles, J. M. Martinez-Tarifa, M. V. Rojas-Moreno, R. Albarracin, and J. Ardila-Rey, "Antenna selection and frequency response study for UHF detection of partial discharges," 2012 IEEE I2MTC - Int. Instrum. Meas. Technol. Conf. Proc., pp. 1496-1499, 2012.

[14]F. Wang, F. Bin, Q. Sun, J. Fan, F. Liang, and X. Xiao, "A novel UHF Minkowski fractal antenna for partial discharge detection," Microw. Opt. Technol. Lett., vol. 59, no. 8, pp. 1812-1819, 2017.

[15] S. M. Mukhtar, M. Isa, and A. Abdullah Al-Hadi, "Design of UHF Antenna Sensor for Partial Discharge Detection in High Voltage S ubstation," IOP Conf. Ser. Mater. Sci. Eng., vol. 318, no. 1, 2018.

[16]H. F. Ye, Q. Yong, D. Yue, G. H. Sheng, and X. C. Jiang, "Development of multi-band ultra-high-frequency sensor for partial discharge monitoring based on the meandering technique," IET Sci. Meas. Technol., vol. 8, no. 5, pp. 327-335, 2014.

[17]D. K. Mishra, B. Sarkar, C. Koley, and N. K. Roy, "Characterisation of Microstrip patch antenna based UHF sensor for detection of partial discharge," 12th IEEE Int. Conf. Electron. Energy, Environ. Commun. Comput. Control (E3-C3), INDICON 2015, pp. 1-6, 2016.

[18] B. D. Orban and G. J. K. Moernaut, "The Basics of Patch Antennas , Updated," 2005.

[19] C. a. Balanis, "Antenna Theory: Analysis and Design," vol. 28, no. 3, 2012.

[20] S. Bisht, S. Saini, V. Prakash, and B. Nautiyal, "Study The Various Feeding Techniques of Microstrip Antenna Using Design and Simulation Using CST Microwave Studio,” Int. J. Emerg. Technol. Adv. Eng., vol. 4, no. 9, pp. 318-324, 2014.

[21] U. Kashyap, Sreenath \& Raithatha, "Microstrip Patch Antenna for ISM Band Applications," Int. J. Emerg. Technol. Adv. Eng., vol. 5, 2015. 